\title{
Reliability of AIN/Sapphire bilayer structure for high-temperature SAW applications
}

\author{
Thierry AUBERT, Omar ELMAZRIA, Badreddine ASSOUAR, Ahmad HAMDAN, Damien GENÈVE \\ Institut Jean Lamour \\ UMR 7198 CNRS - Nancy University \\ 54506 Vandoeuvre-lès-Nancy, France \\ thierry.aubert@1pmi.uhp-nancy.fr
}

\begin{abstract}
This paper explores the possibility to use AlN/sapphire bilayer structure as piezoelectric material for high-temperature SAW applications in air atmosphere. In order to verify the temperature stability of AIN, homemade AIN/Sapphire samples were annealed during 2 to 20 hours, at temperatures going from 700 to $1000^{\circ} \mathrm{C}$, before being characterized by $e x$ situ X-ray diffraction (XRD), ellipsometry and secondary ion mass spectroscopy (SIMS). Ex situ SAW measurements were used to transfer the obtained results to the SAW field, while in situ investigations were conducted up to $500^{\circ} \mathrm{C}$ to observe the effect of temperature on the SAW signal.
\end{abstract}

Keywords-high temperature; AlN; sapphire ; SAW; langasite

\section{INTRODUCTION}

Surface acoustic wave (SAW) devices are key components of telecommunication systems for more than thirty years. They also constitute a very promising solution for sensors applications, as they are very sensitive to the external environment, while being remotely requestable and passive. This last property is particularly interesting in harsh environments, such as high temperatures up to $1000^{\circ} \mathrm{C}$, where this technology offers the possibility to achieve wireless sensors [1].

The choice of the piezoelectric substrate, which is an essential part of SAW devices, is one of the challenges to face to realize such sensors. Indeed, there are very few piezoelectric materials capable of withstanding high temperatures above $500^{\circ} \mathrm{C}$ [2]. Up to now, the most promising results have been obtained with langasite $\left(\mathrm{La}_{3} \mathrm{Ga}_{5} \mathrm{SiO}_{14}\right.$ or LGS). In particular, Pereira da Cunha et al. have successfully tested this material for $5 \frac{1}{2}$ months at $800^{\circ} \mathrm{C}$ [3]. Moreover, Hornsteiner et al. have measured a SAW signal on an LGS-based device up to $1085^{\circ} \mathrm{C}$
[4]. Last but not least, good quality LGS-wafers are commercially available. However, LGS is also characterized by some weaknesses. In particular, its acoustic propagation losses increase drastically with frequency and temperature, which restrains its use in wireless mode to the $434 \mathrm{MHz}-\mathrm{ISM}$ band, excluding the more promising $2.45 \mathrm{GHz}$ one [5]. Furthermore, the high-temperature properties of LGS have been mainly investigated in air atmosphere, but its behavior is unknown in most industrial gas environments $\left(\mathrm{NH}_{\mathrm{x}}, \mathrm{SO}_{2}, \mathrm{H}_{2}\right.$, etc). For these two reasons, alternatives to LGS would be of great interest.

Aluminium nitride (AlN) thin films could be one of these. It has been identified as a potential candidate for hightemperature SAW applications more than 10 years ago $[4,6]$. Indeed, this material is chemically stable up to $1040^{\circ} \mathrm{C}$ in vacuum [7], $1200^{\circ} \mathrm{C}$ in $\mathrm{N}_{2} / \mathrm{H}_{2}$ mixture [8] and is expected to oxidize in air atmosphere in the $800^{\circ} \mathrm{C}$-range [9]. Furthermore, showing the highest SAW velocity among the piezoelectric materials, it is particularly suited to carry out devices operating at high frequencies such as $2.45 \mathrm{GHz}$ [10]. Eventually, some high-quality AlN films show acoustic propagation losses well lower than those of LGS (Tab. 1).

Despite all these potentialities, AlN has hardly been experimentally studied as piezoelectric material for hightemperature SAW applications. We have recently demonstrated that IDT(Pt/Ta)/AlN/Sapphire SAW structure withstands temperatures as high as $900^{\circ} \mathrm{C}$ for short-time exposure of 30 minutes [11]. Now, the goal of the present study is to investigate the reliability of the AlN/Sapphire bilayer structure for long time applications at high temperatures, in order to verify its potential as an alternative structure to the LGS family, especially for high frequency applications.

TABLE I. COMPARISON BETWEEN SAW PROPERTIES OF LGS AND ALN/SAPPHIRE BILAYER STRUCTURE [2]

\begin{tabular}{|c|c|c|c|}
\hline & $\begin{array}{c}\text { SAW } \\
\text { velocity } \\
(\mathbf{m} / \mathbf{s})\end{array}$ & $\begin{array}{c}\text { Electromechanical } \\
\text { coupling coefficient } \mathbf{K}^{\mathbf{2}} \\
(\boldsymbol{\%})\end{array}$ & $\begin{array}{c}\text { Acoustic propagation } \\
\text { losses at 1 GHz } \\
(\mathbf{m d B} / \boldsymbol{\lambda})\end{array}$ \\
\hline Langasite $\left(0^{\circ}, 138.5^{\circ}, 26.6^{\circ}\right)$ & 2700 & 0.44 & 0.7 \\
\hline (002)AlN/(0001)sapphire & 5700 & 0.3 & 4 \\
\hline
\end{tabular}




\section{EXPERIMENTAL}

1,3 $\mu$ m-thick hetero-epitaxial (002) AlN thin films were deposited by reactive magnetron sputtering onto (0001) sapphire substrates. The microstructure of the films was investigated by X-ray diffraction (XRD) and transmission electron microscopy (TEM), while atomic force microscopy (AFM) gave access to its morphology.

To study the temperature stability of AlN in air atmosphere, the AlN/Sapphire samples were annealed at temperatures between 700 and $1000^{\circ} \mathrm{C}$, for periods going from 2 to 20 hours. The effects of high-temperature exposure were then studied by XRD, ellipsometry and secondary ion mass spectroscopy (SIMS). To confirm and transfer these results to the SAW field, the SAW signals coming from delay lines with aluminium electrodes, operating at 560 and $710 \mathrm{MHz}$, performed on both as-deposited and annealed samples, were compared.

$\mathrm{Pt} / \mathrm{Ta}$ IDTs (which means $10 \mathrm{~nm}$ of tantalum as adhesion layer and $100 \mathrm{~nm}$ of platinum as electrode [12]) were also implemented in order to achieve in situ SAW measurements with a probe station, up to $500^{\circ} \mathrm{C}$.

\section{RESULTS AND DISCUSSION}

\section{A. Hetero-epitaxial AlN thin films on sapphire}

XRD measurements and TEM revealed that the (002) AIN films are stress-free, while being highly-textured out of the plane, with a full width at half-maximum (FWHM) of the (002) rocking-curve $(\mathrm{RC})$ as low as $0.26^{\circ}$, as well as in the plane (Fig. 1). The value of the grain size, obtained from XRD measurements via the Scherrer formula [13], confirmed by $\mathrm{AFM}$, is close to $30 \mathrm{~nm}$. The latter also give the roughness of the films which value (Rms), equal to $8 \AA$, is suitable for SAW applications.

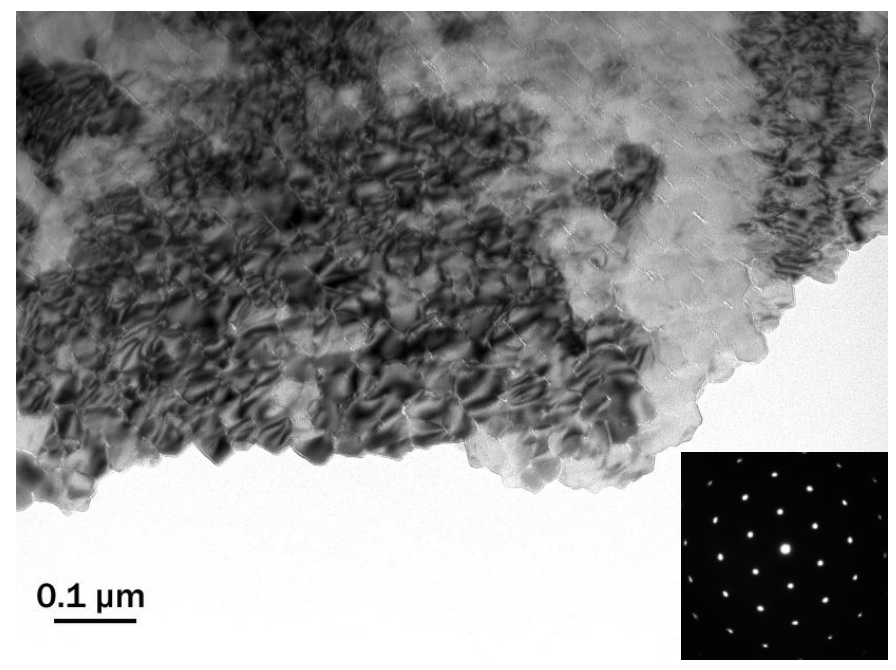

Figure 1. TEM image and SAED pattern of the optimized AlN films

\section{B. Temperature stability of AlN in air atmosphere}

$\mathrm{XRD}$ measurements point out that, up to $900^{\circ} \mathrm{C}$, neither the stress, nor the grain size nor the texture of the films are modified by the high-temperature exposure (Fig. 2). On the other side, the intensity of the (002) AlN peak promptly decrease during the annealing process, from $900^{\circ} \mathrm{C}$ (Fig. 3). As this phenomenon cannot be related, at least at $900^{\circ} \mathrm{C}$, to a modification of the microstructure of the films, its origin has to be found in the shrinking of the AlN amount, associated to a strong oxidation. The results obtained at 700 and $800^{\circ} \mathrm{C}$ are more uncertain, the formed oxide overlayer being likely too thin to be precisely detected by ex situ XRD measurements. Thus, more sensitive methods, such as SIMS or ellipsometry were used to provide a clearer picture of the situation at these lower temperatures.

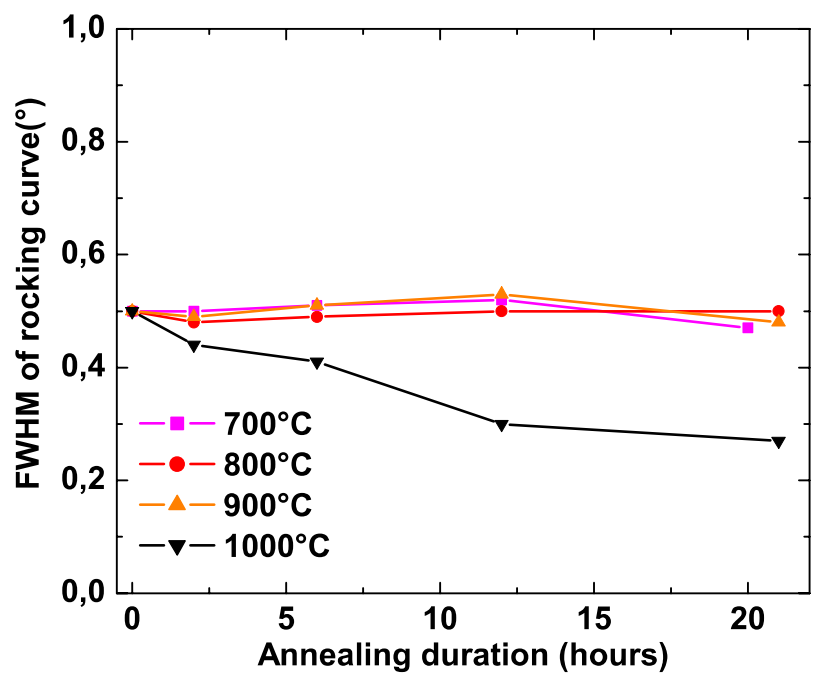

Figure 2. FWHM of the RC (002) as a function of the annealing duration

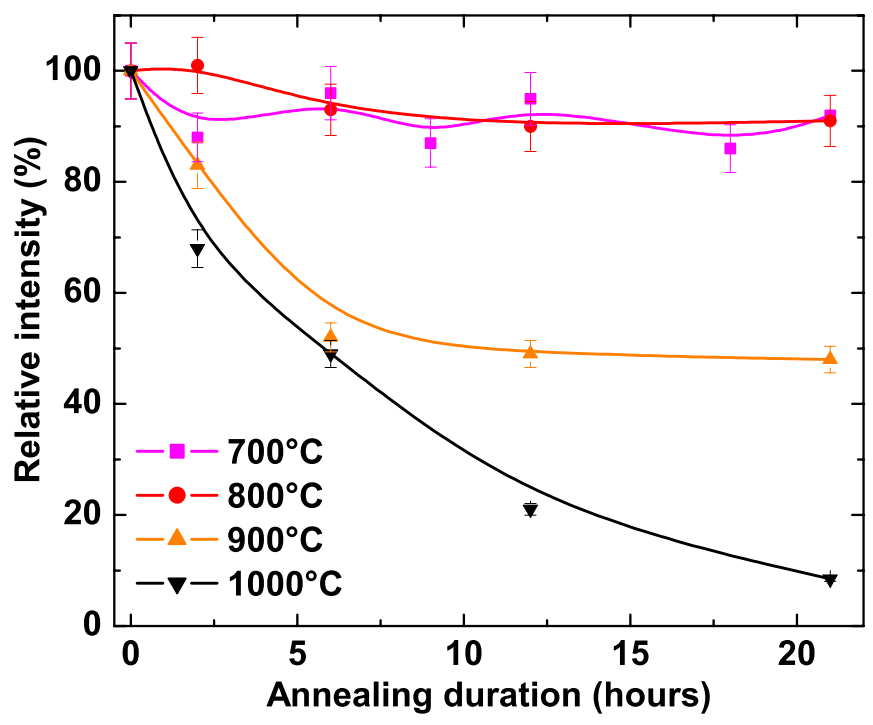

Figure 3. Intensity of the (002) XRD AIN peak as a function of the annealing duration 
The results given by the latter perfectly converge (Fig. $4 \& 5)$. They both highlight the presence of a thin $(\approx 10 \mathrm{~nm}-$ thick) native oxide layer at the surface of the AlN films. This thickness slightly increases after 2 hours of annealing at 700 and $800^{\circ} \mathrm{C}$ but remains comparable to that of the native one, which is not the case at higher temperatures, thereby confirming XRD measurements. The most important result appears after 20 hours of annealing. Whereas the thickness of the oxide layer continues to slightly increase at $800^{\circ} \mathrm{C}$, reaching approximately $50 \mathrm{~nm}$ at the end of the process, it seems that the initial oxidation passivates $\mathrm{AlN}$ films from further aggression at $700^{\circ} \mathrm{C}$.

In order to validate this key result in the SAW field, we compared the $\left|S_{21}\right|$ signal given by delay lines performed with aluminium IDTs on both as-deposited and $700^{\circ} \mathrm{C}$-annealed samples. This special procedure has been followed to overcome the limitation of our in situ facilities which cannot be used over $600^{\circ} \mathrm{C}$. One can observe on Fig. 6 that the technological dispersion makes the interpretation of the results quite difficult. However, it seems that no systematic frequency shift related to the $700^{\circ} \mathrm{C}$-annealing process of the AlN/Sapphire samples can be detected. This is a fundamental result in the context of the use of AIN in SAW sensors. On the other side, insertion losses seem increase slightly, probably because of the initial growth of the thin oxide overlayer. Note however that some devices carried out on annealed samples show the same losses as those prepared on as-deposited samples.

\section{In situ SAW measurements}

One can observe on Fig. 7 that, except a slight increase in the insertion losses of $0.01 \mathrm{~dB} /{ }^{\circ} \mathrm{C}$, there is no deterioration of the SAW signal when the device goes from $20^{\circ} \mathrm{C}$ to $500^{\circ} \mathrm{C}$. The latter exhibits a large and quasi-constant sensitivity to the temperature, with temperature coefficient of frequency (TCF) values going from $-68 \mathrm{ppm} /{ }^{\circ} \mathrm{C}$ at $20^{\circ} \mathrm{C}$ to $-80 \mathrm{ppm} /{ }^{\circ} \mathrm{C}$ at $500^{\circ} \mathrm{C}$, making it well suited for temperature sensor applications. Note that the direction of propagation of the SAW was here along the $\mathrm{Y}$-axis of the sapphire substrate, and that the relative thickness of AIN $(2 \pi \cdot h / \lambda$, where $h$ is the thickness of the AlN film) was quite limited, with a value of 0.5 .

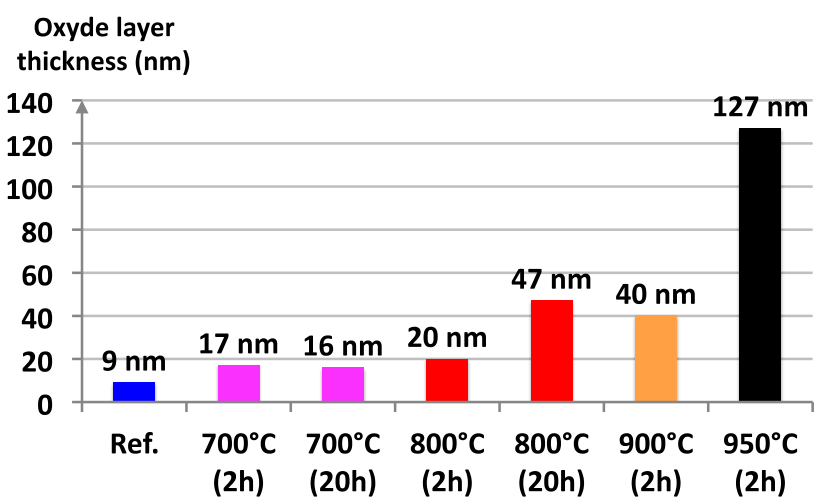

Figure 4. Thickness of the oxide overlayer determined by ellipsometry

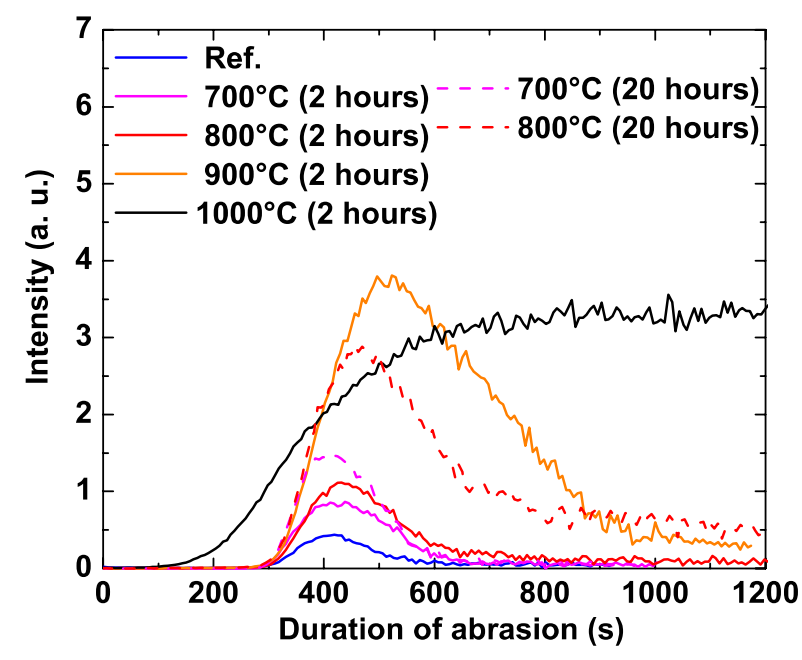

Figure 5. SIMS depth profile signal related to oxygen

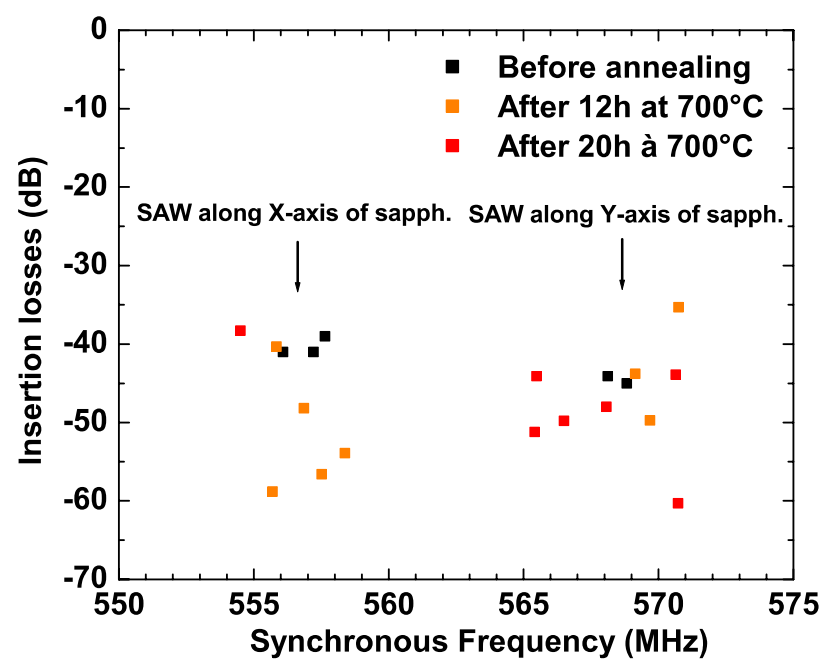

Figure 6. Insertion losses and synchronous frequency of several delay lines carried out on as-deposited $\mathrm{AlN}$ films and $700^{\circ} \mathrm{C}$-annealed ones

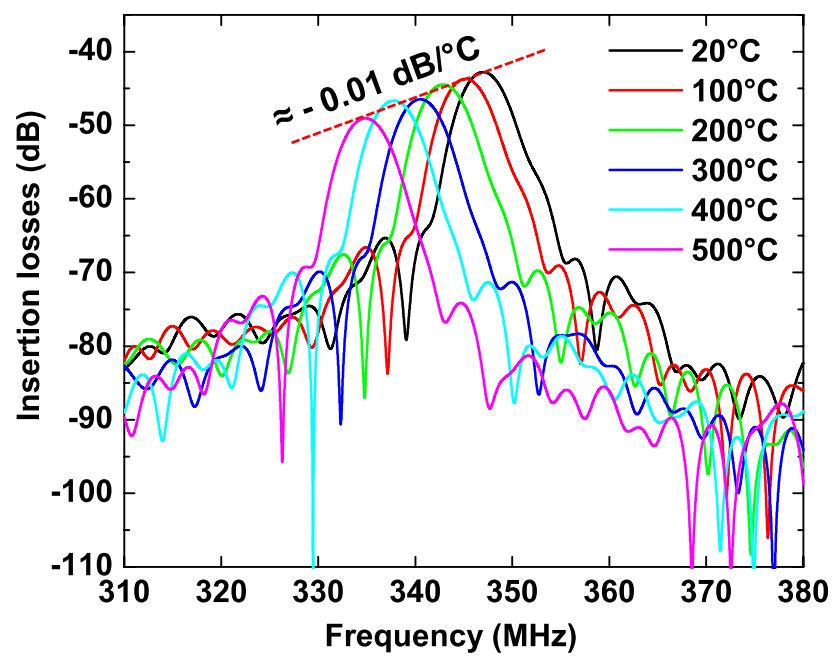

Figure 7. $\left|\mathrm{S}_{21}\right|$ signal of an IDT (Pt/Ta)/AlN/Sapphire SAW delay line, from 20 to $500^{\circ} \mathrm{C}$ 


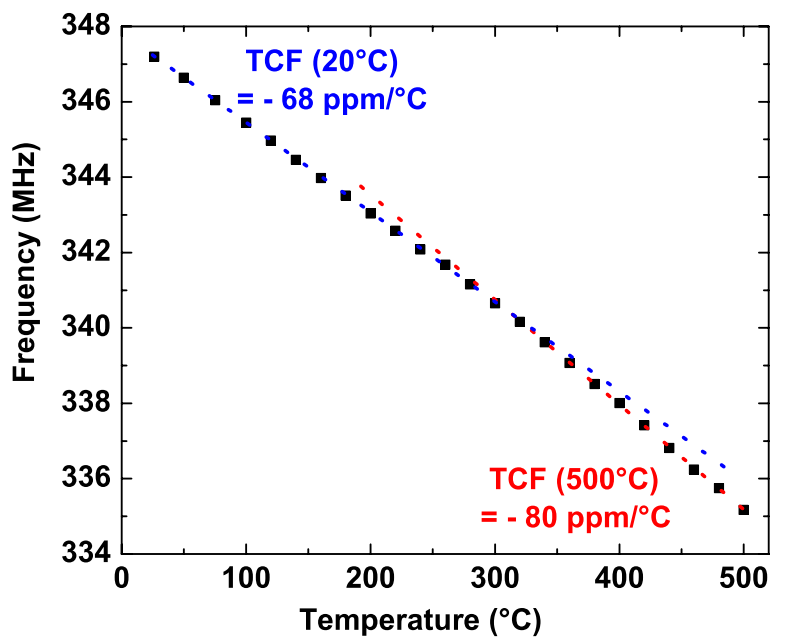

Figure 8. Temperature dependence of the synchronous frequency of the delay line

\section{CONCLUSION AND OUTLOOKS}

The results obtained throughout this study suggest that AlN can be used as piezoelectric material for SAW sensors operating up to $700^{\circ} \mathrm{C}$ in air atmosphere, as the oxidation process seems to be insignificant, which is not the case at higher temperatures. This statement will have to be confirmed by in situ SAW measurements conducted up to this temperature. Anyway, better stability of AlN is expected in environments less aggressive than air, such as those containing small amounts of oxygen, where temperature as high as $1000^{\circ} \mathrm{C}$ could be reached [8]. Eventually, the AlN/Sapphire bilayer structure could have an enormous hidden potential for high-temperature SAW applications, as the IDTs could be placed below the AIN film. Thus, AlN/IDT/AIN/Sapphire or AlN/IDT/Sapphire are promising solution leading to protect both IDTs from agglomeration phenomena and active piezoelectric area of AlN from oxidation, or other chemical aggression, not to mention that this would significantly improve the electromechanical coupling coefficient $\mathrm{K}^{2}$ of the structure [10].

\section{REFERENCES}

[1] R. Fachberger, G. Bruckner, R. Hauser, C. Ruppel, J. Biniasch and L. Reindl, "Properties of radio frequency Rayleigh waves on langasite at elevated temperature," Proc. IEEE Ultrasonics Symp., 2004, pp 12231226.

[2] T. Aubert, O. Elmazria and B. Assouar, "Wireless and batteryless surface acoustic wave sensors for high temperature environments," Proc. of the $9^{\text {th }}$ Inter. Conf. on Electronic Measurement \& Instruments (ICEMI), 2009, pp. 2-890-898.

[3] M. Peireira da Cunha, R. J. Lad, T. Moonlight, G. Bernhardt and D. J. Frankel, "High temperature stability of langasite surface acoustic wave devices," Proc. IEEE Ultrasonics Symp., 2008, pp. 205-208.

[4] J. Hornsteiner, E. Born, G. Fischerauer and E. Riha, "Surface acoustic wave sensors for high temperature applications," Proc. IEEE Int. Freq. Contr. Symp., 1998, pp. 615-620.

[5] R. Fachberger, G. Bruckner, R. Hauser, C. Ruppel, J. Biniasch and L. Reindl, "Properties of radio frequency Rayleigh waves on langasite at elevated temperature," Proc. IEEE Ultrasonics Symp., 2004, pp. 12231226
[6] D. Damjanovic, "Materials for high temperature piezoelectric transducers," Current Opinion in Solid State and Materials Science, Vol. 3,1998, pp. 469-473

[7] O. Ambacher, M. S. Brandt, R. Dimitrov, T. Metzger, M. Stutzmann, R. A. Fisher, A. Miehr, A. Bergmaier and G. Dollinger, "Thermal stability and desorption of Group III nitrides prepared by metal organic chemical vapor deposition," J. Vac. Sci. Technol. B, Vol. 14(6), 1996, p 3532 3542

[8] C.-Y. Lin and F.-H. Lu, "Oxidation behavior of AlN films at high temperature under controlled atmosphere," J. Eur. Ceram. Soc., Vol. 28, 2008, pp. 691-698

[9] J. Chaudhuri, L. Nyakiti, R.G. Lee, Z. Gu, J.H. Edgar and J.G. Wen, "Thermal oxidation of single crystalline aluminum nitride," Materials Characterization, Vol. 58, 2007, pp. 672-679.

[10] C. Caliendo, "Theoretical and experimental investigation of gigahertzband, temperature-compensated electromechanical coupling configurations based on AlN films," Appl. Phys. Lett., Vol. 92, 2008, 033505 .

[11] Thierry Aubert, Omar Elmazria, Badreddine Assouar, Laurent Bouvot and M. Oudich, "Surface acoustic wave devices based on AlN/Sapphire structure for high temperature applications," Appl. Phys. Lett., Vol. 96, 2010, 203503. 